\title{
Collateral Scoring on CT Angiogram Must Evaluate Phase and Regional Pattern
}

\author{
Colin Casault, Abdulaziz S. Al Sultan, Anurag Trivedi, Sung Il Sohn, Emmad \\ Qazi, Matthew Bokyo, Mohammed Almekhlafi, Christopher d'Esterre, Mayank \\ Goyal, Andrew M. Demchuk, Bijoy K. Menon
}

\begin{abstract}
Purpose: We measured anterior cerebral artery (ACA)-middle cerebral artery (MCA) and posterior cerebral artery (PCA)MCA pial filling on single-phase computed tomography angiograms (sCTAs) in acute ischemic stroke and correlate with the CTA-based Massachusetts General Hospital (MGH) and digital subtraction angiography (DSA)-based American Society of Interventional and Therapeutic Neuroradiology (ASITN) score. Methods: Patients with acute stroke and M1 MCA \pm intracranial internal carotid artery occlusion on baseline CTA were included. Baseline sCTA was assessed for phase of image acquisition. An evaluator assessed collaterals using the Calgary Collateral (CC) Score (measures pial arterial filling in ACA-MCA and PCA-MCA regions separately), the CTA-based MGH score, and on DSA using the ASITN score. Infarct volumes were measured on 24- to 48-hour magnetic resonance imaging/ computed tomography. Results: Of 106 patients, baseline sCTA was acquired in early arterial phase in 9.9\%, peak arterial in $50.7 \%$, equilibrium in $32.4 \%$, early venous in $5.6 \%$, and late venous in $1.4 \%$. Variance in ACA-MCA collaterals explained only $32 \%$ of variance in PCA-MCA collaterals on the CC score (Spearman's correlation coefficient rho [rho] =0.56). Correlation between ACA-MCA collaterals and the MGH score was strong ( $\mathrm{rho}=0.8)$; correlation between PCA-MCA collaterals and this score was modest $($ rho $=0.54)$. Correlation between ACA-MCA collaterals and the ASITN score was modest $(\mathrm{n}=53$, rho $=0.43)$; and correlation between PCA-MCA collaterals and ASITN score was poor (rho=0.33). Of the CTA-based scores, the CC Score (Akaike [AIC] 1022) was better at predicting follow-up infarct volumes than was the MGH score (AIC 1029). Conclusion: Collateral assessments in acute ischemic stroke are best done using CTA with temporal resolution and by assessing regional variability. ACA-MCA and MCA-PCA collaterals should be evaluated separately.
\end{abstract}

RÉSUMÉ: La mesure de la circulation collatérale au moyen de l'angiographie par tomodensitométrie doit évaluer les phases de remplissage et la variabilité régionale du cerveau. Objectif: Nous avons mesuré le remplissage piale de l'artère cérébrale antérieure (ACA) à l'artère cérébrale moyenne (ACM), et de l'artère cérébrale postérieure ( $\mathrm{ACP}$ ) à l'ACM, au moyen d'une angiographie par tomodensitométrie à phase unique (single-phase) dans le cas de patients victimes d'un accident ischémique cérébral aigu. Nous avons ensuite corrélé nos résultats avec les scores obtenus à l'aide d'angiographies par tomodensitométrie au Massachusetts General Hospital (MGH) et d'angiographies numériques avec soustraction de l'American Society of Interventional and Therapeutic Neuroradiology (ASITN). Méthodes: Nous avons inclus des patients victimes d'un AVC aigu et d'une occlusion de la carotide interne intracrânienne M1 MCA \pm détectés au moyen d'angiographies par tomodensitométrie servant de référence (baseline). Ces mêmes angiographies ont été ensuite évaluées lors de la phase d'acquisition des images. Un évaluateur a aussi analysé la circulation collatérale à l'aide du score Calgary Collateral (CC), lequel mesure séparément le remplissage artériel piale de l'ACA à l'ACM, et de l'ACP à l'ACM, et du score du MGH. Quant aux angiographies numériques avec soustraction, nous avons fait appel au score de l'ASITN. Le volume des infarctus a été mesuré au moyen de techniques d'imagerie par résonance magnétique et de tomographie par ordinateur, et ce, pendant 24 à 48 heures. Résultats: Sur 106 patients, les données des angiographies par tomodensitométrie ont été obtenues chez 9,9\% d'entre eux lors de la phase artérielle précoce; lors de la phase artérielle maximale, chez 50,7 \% d'entre eux ; lors de la phase d'équilibre, chez 32,4\% d'entre eux ; lors de la phase veineuse précoce, chez 5,6\% d'entre eux; et enfin, lors de la phase veineuse tardive, chez $1,4 \%$ d'entre eux. La variance de la circulation collatérale de l'ACA à l'ACM n'a expliqué que $32 \%$ de la variance de la circulation collatérale de l'ACP à l'ACM en lien avec le score CC (coefficient de corrélation de Spearman; rho = 0,56). La corrélation entre la circulation collatérale de l'ACA à l'ACM et le score du MGH s'est avérée marquée (rho = 0,8); la corrélation entre la circulation collatérale de l'ACP à l'ACM et ce même score s'est révélée plus faible (rho $=0,54$ ). De son côté, la corrélation entre la circulation collatérale de l'ACA à l'ACM et le score de l'ASITN est apparue encore plus faible $(\mathrm{n}=53$; rho $=0,43)$ tandis que la corrélation entre la circulation collatérale de l'ACP à l'ACM et le score de l'ASITN (rho) n'a été que de 0,33 . De tous les scores obtenus à l'aide d'angiographies par tomodensitométrie, le score CC (critère d'information d'Akaike ou AIC = 1022) a mieux réussi à prédire les volumes d'infarctus subséquents que celui du MGH (AIC = 1029). Conclusions: Il est préférable d'évaluer la circulation collatérale dans le cas d'accidents ischémiques cérébraux aigus au moyen d'angiographies par tomodensitométrie servant de référence, et ce, en fonction du

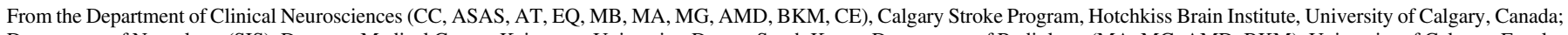

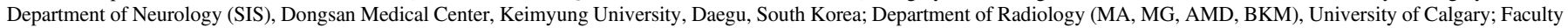

of Medicine (MA), King Abdulaziz University, Saudi Arabia; Department of Community Health Sciences (BKM), University of Calgary, Calgary, Alberta, Canada. Received January 11, 2016. Final Revisions Submitted February 15, 2017. Date of acceptance February 17, 2017.

Correspondence to: Bijoy K. Menon, Department of Community Health Sciences, University of Calgary, 1079 A, 29th Street NW, Calgary, AB, Canada T3H4J2.

Email: Bijoy.Menon@Albertahealthservices.ca 
temps et en analysant la variabilité régionale du cerveau. On devrait aussi évaluer séparément la circulation collatérale de l'ACA à l'ACM et celle de l'ACP à l'ACM.

Keywords: Collaterals, Vascular Neurology, Stroke Imaging, Vascular Imaging

doi:10.1017/cjn.2017.53

Can J Neurol Sci. 2017; 44: 503-507

In patients with acute ischemic stroke (AIS), collaterals provide blood flow to tissue at risk via arterial backfilling. Good collateral status measured on computed tomography angiogram (CTA) is associated with improved imaging and clinical outcome. ${ }^{1-4}$ Various imaging modalities are used to measure collateral status in patients with acute ischemic stroke. Magnetic resonance angiography and transcranial Doppler are noninvasive techniques; however, they are logistically challenging and may not be available at all centres. Alternatively, the reference standard, the four-vessel digital subtraction angiogram (DSA), is invasive. Finally, CTA is readily available at many centres, and only adds minutes to the noncontrast $\mathrm{CT}$ acquisition.

For an imaging modality to be considered as a reasonable standard for measuring collateral status, it must have biological validity. In a previous study, Menon et $\mathrm{al}^{5}$ found significant variability in collateral status within the middle cerebral artery (MCA) ischemic region. The anterior cerebral artery (ACA)MCA collaterals behaved differently to the posterior cerebral artery (PCA)-MCA collaterals. This regional variance in collateral status correlates well with brain tissue viability and therefore clinical outcomes. The current reference standard for collateral assessment (i.e. American Society of Interventional and Therapeutic Neuroradiology [ASITN] score on conventional angiogram) or other methods of assessment of collaterals on CTA do not account for this regional variation in collateral status. Of note, collateral assessment on conventional angiograms is almost always restricted to scoring collaterals on images obtained from single arterial injections into the ipsilesional common carotid or internal carotid artery, thus not measuring PCA-MCA collaterals.

In this study, we measure ACA-MCA and PCA-MCA pial filling independently on single-phase CTA (sCTA) ${ }^{6}$ and correlate it with the CTA-based Massachusetts General Hospital (MGH) ${ }^{4}$ and digital subtraction angiography (DSA)-based ASITN collateral score. ${ }^{7}$ We hypothesize that ACA-MCA collaterals (as is done by the ASITN score on conventional angiogram and to a lesser extent by the MGH score on CTA) only capture a small proportion of the variance in PCA-MCA collateral extent.

\section{METHODS}

Patient imaging data were collected from the Calgary Identifying Novel Approaches to Optimize Arterial Imaging Interpretation for Predicting and Measuring Recanalization Whatever the Treatment and to Optimize Parenchymal Imaging Interpretation for Prediction of Early Neurological Recovery After Recanalization Using Serial CT Angiography prospective imaging registry. Each patient underwent a baseline noncontrast CT and CTA . Patients selected to undergo endovascular therapy had DSA. Noncontrast CT was obtained with a 5-mm slice thickness and $140 \mathrm{kVP}$. Next, CTA imaging was acquired from aortic arch to vertex (1-mm slice thickness, $120 \mathrm{kVP})$ using a 100-ml bolus of Optiray 320 contrast.

A total of 106 patients with AIS and a proximal occlusion were included in our study. Each of these patients presented with an M1 $\mathrm{MCA} \pm$ intracranial ICA occlusion on baseline CTA. Phase of image acquisition on baseline CTA was assessed in accordance with the previously published methodology by Rodriquez-Luna et $\mathrm{al}^{8}$ (Table 1). The phase (early, peak arterial, equilibrium, early, late venous) was determined by evaluating Hounsfield units (HU) on the contralateral (unaffected) vasculature at the ICA, M1 MCA, superior sagittal sinus, torcula, and transverse/sigmoid sinus. The contralateral vasculature was chosen to measure the HU to minimize the potential impact from the proximal occlusion on the ipsilateral side.

Collaterals beyond the M1 MCA occlusion were assessed using the Calgary Collateral (CC) Score (Table 2). This score measures pial arterial filling in ACA-MCA and PCA-MCA regions separately on a 5-point ordinal scale (Figure 1). These scores are then added to obtain a 10-point score. Additionally, the evaluator assessed collateral status on CTA and DSA using the MGH score and ASITN score. These scores measure collateral status in the entire ischemic region. These scores are also described in Table 2. Quantomo (Cybertrial Inc., Calgary), a validated software tool, was used to measure infarct volume in millilitres on 24- to 48-hour follow-up MRI (or CT when MRI was not available) while being blinded to all other clinical and imaging information. Manual adjustments to delineate infarct boundaries were performed where necessary. If the infarct showed haemorrhagic conversion, the hemorrhage regions were incorporated within the boundaries of infarct.

The three scores were compared with each other using nonparametric statistics (Spearman's correlation coefficient rho [rho]). Linear regression was used to assess the relationship between collateral status and infarct volume on follow-up after verifying if relevant statistical assumptions were met. Information

Table 1: HU thresholds defining phase of image acquisition ${ }^{17}$

\begin{tabular}{l|l|l}
\hline Phase & Arterial HU & Venous HU \\
\hline Early arterial & Higher than venous vasculature & $\leq 200$ \\
\hline Peak arterial & $\begin{array}{c}\geq 100 \text { higher than venous } \\
\text { vasculature }\end{array}$ & $>200$ \\
\hline Equilibrium & $\begin{array}{l}<100 \text { higher or equal to venous } \\
\text { vasculature }\end{array}$ & $>200$ \\
\hline Peak venous & $>200$ & $\begin{array}{c}\text { Higher than arterial } \\
\text { vasculature }\end{array}$ \\
\hline Late venous & $\leq 200$ & $\begin{array}{c}\text { Higher than arterial } \\
\text { vasculature }\end{array}$ \\
\hline
\end{tabular}

$\mathrm{HU}=$ Hounsfield unit. 


\section{Table 2: The Calgary Collateral Score, the ASITN score on DSA and the MGH score}

\begin{tabular}{|c|c|c|}
\hline Calgary Collateral Score & ASITN Score & MGH Score \\
\hline $\begin{array}{l}\text { None (0) } \\
\text { - Compared to the asymptomatic contralateral hemisphere, } \\
\text { there are no vessels visble within the occluded vascular territory }\end{array}$ & $\begin{array}{l}\text { Grade } 0 \\
\text { - Compared to the asymptomatic contralateral hemisphere, there } \\
\text { are no vessels visible within the occluded vascular territory }\end{array}$ & $\begin{array}{c}\text { Grade } 1 \\
\bullet \quad \text { Absent }\end{array}$ \\
\hline $\begin{array}{l}\text { Minimal (1) } \\
\text { - Compared to the asymptomatic contralateral hemisphere, } \\
\text { there are few vessels visible in the occluded territory }\end{array}$ & $\begin{array}{l}\text { Grade } 1 \\
-\quad \text { Slow collateral to the periphery of the ischemic site }\end{array}$ & $\begin{array}{l}\text { Grade } 2 \\
\text { - Less than the contralateral } \\
\text { unaffected side }\end{array}$ \\
\hline $\begin{array}{l}\text { Poor (2) } \\
\text { - Compared to the asymptomatic contralateral hemisphere, } \\
\text { there is decreased vessel prominence and extent with } \\
\text { regions without vessels in some parts of the occluded territory }\end{array}$ & $\begin{array}{l}\text { Grade } 2 \\
\text { - Rapid collaterals to the periphery of the ischemic territory } \\
\text { with some remaining defect in the ischemic territory }\end{array}$ & $\begin{array}{l}\text { Grade } 3 \\
\text { - Equal to the contralateral } \\
\text { unaffected side }\end{array}$ \\
\hline $\begin{array}{l}\text { Fair (3) } \\
\text { - Compared to the asymptomatic contralateral hemisphere, } \\
\text { there is moderately reduced prominence and extent of pial } \\
\text { vessels beyond the occluded artery within the symptomatic } \\
\text { hemisphere }\end{array}$ & $\begin{array}{l}\text { Grade } 3 \\
\text { - Collaterals with slow but complete angiographic blood flow } \\
\text { into the ischemic territory by the late venous phase }\end{array}$ & $\begin{array}{l}\text { Grade } 4 \\
\text { - More than the contralateral } \\
\text { unaffected side }\end{array}$ \\
\hline $\begin{array}{l}\text { Good (4) } \\
\text { - Compared to the asymptomatic contralateral hemisphere, } \\
\text { there is slightly reduced prominence and extent of pial } \\
\text { vessels beyond the occluded artery within the symptomatic } \\
\text { hemisphere }\end{array}$ & $\begin{array}{l}\text { Grade } 4 \\
\text { - Complete and rapid collateral blood flow to the vascular bed } \\
\text { in the entire ischemic territory by retrograde perfusion }\end{array}$ & $\begin{array}{l}\text { Grade } 5 \\
-\quad \text { Exuberant }\end{array}$ \\
\hline $\begin{array}{l}\text { Excellent (5) } \\
\text { - Compared to the asymptomatic contralateral hemisphere, } \\
\text { there is increased or normal prominence and extent of pial } \\
\text { vessels beyond the occluded artery within the symptomatic } \\
\text { hemisphere }\end{array}$ & & \\
\hline
\end{tabular}

Note the Calgary Collateral score is scored separately in the ACA-MCA and PCA-MCA regions for a total score of $10 .{ }^{4,13}$ 


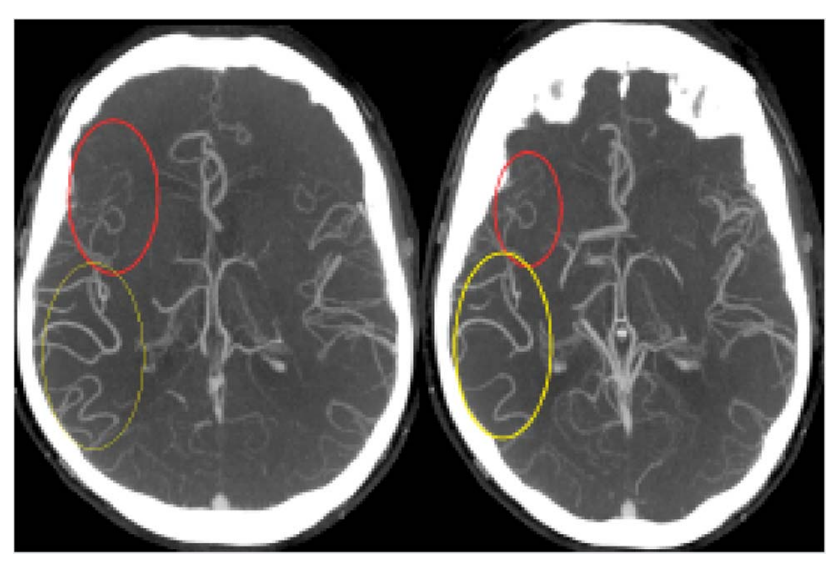

Figure 1: Single phase computed tomography angiography demonstrating posterior cerebral artery (PCA)-middle cerebral artery (MCA) dominant collateral pattern in a patient with M1 MCA occlusion. In addition to exuberant MCA-PCA filling (yellow circle), there is poor anterior cerebral artery-MCA filling seen (red circle).

theory approaches (Akaike [AIC] and Bayesian Information Criterion [BIC]) were used to determine which CTA model best predicted follow-up infarct volumes.

\section{RESUlts}

A total of 106 patients were included in the analysis. Baseline sCTA was acquired in early arterial phase in $9.9 \%$, peak arterial in $50.7 \%$, equilibrium in $32.4 \%$, early venous in $5.6 \%$, and late venous in $1.4 \%$ (Figure 2). Scans acquired in the very early arterial phase or late venous phase were excluded from further analysis.

A modest correlation was observed between ACA-MCA and PCA-MCA collaterals using the CC Score. Only $32 \%$ of the variance in PCA-MCA collaterals was explained by ACA-MCA collaterals ( $\mathrm{rho}=0.56, \mathrm{p}<0.0001)$.

Correlation between ACA-MCA collaterals and the CTAbased MGH score was strong ( $r h o=0.8, p<0.0001)$; correlation between PCA-MCA collaterals and this score, however, was modest $(r h o=0.54, \mathrm{p}<0.0001)$. Correlation between ACA-MCA collaterals and the DSA based ASITN score was modest $(n=53$, rho $=0.43, \mathrm{p}=0.16$ ) but correlation among PCA-MCA collaterals and ASITN score was poor $(\mathrm{rho}=0.33, \mathrm{p}=0.4)$.

Infarct volume on follow-up scans was measured in 90/106 patients. Mean infarct volume was $51.8 \mathrm{ml}$ (standard deviation, $82.3 \mathrm{ml}$ ). On linear regression, a statistically significant relationship was noted between the CC Score and follow-up infarct

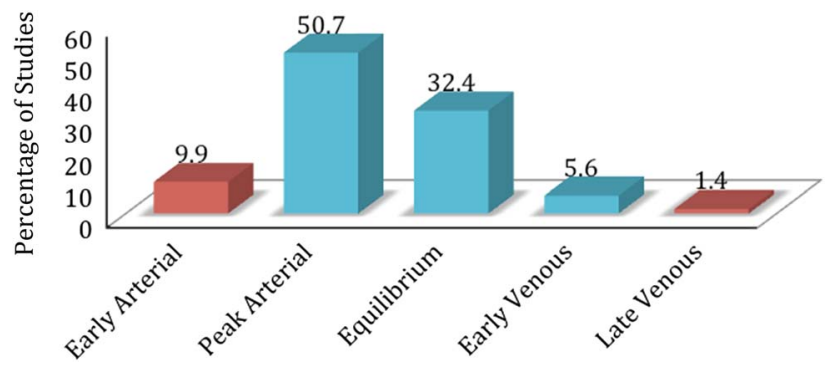

Figure 2: The proportion of patients separated by phase of single phase computed tomography angiography acquisition (early arterial, peak arterial, equilibrium, early venous, late venous) in our study.

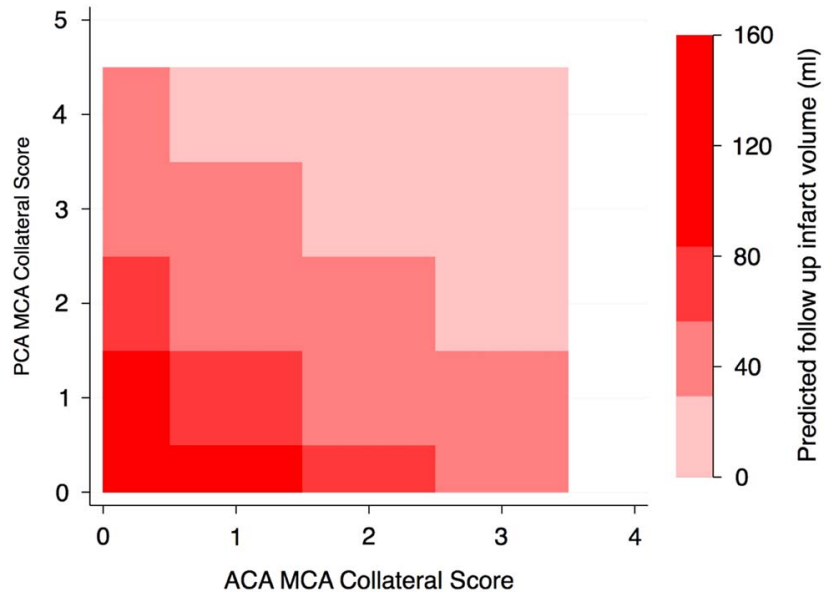

Figure 3: Contour map showing predicted infarct volume on follow-up imaging estimated using anterior cerebral artery (ACA)-middle cerebral artery (MCA) collateral score (x axis) and posterior cerebral artery (PCA)-MCA collateral score (y axis).

volume $(\mathrm{p}<0.001)$ and between the MGH score and follow-up infarct volume $(\mathrm{p}<0.001)$. The statistical model that used the $\mathrm{CC}$ Score (AIC, 1022; BIC, 1027) was a better fit at predicting followup infarct volumes than the MGH score (AIC, 1029; BIC, 1034). Relationship between ACA-MCA and PCA-MCA collateral scores and model derived "predicted follow-up infarction volume" is shown in Figure 3.

\section{DISCUSSION}

Leptomeningeal collaterals act as a system to unify the major cerebral arterial systems and provide a mechanism for retrograde blood flow during AIS. Our results substantiate previous findings showing significant variability in collateral status between ACA-MCA and PCA-MCA collaterals in patients with acute anterior circulation ischemic strokes with M1 MCA occlusions. We also show scoring collaterals on conventional angiograms (using the ASITN score) or on CTA using scores that look at the MCA region as a whole do not capture this regional variability in collateral status. Our results thus support the importance of assessing regional variability in collateral status while scoring them using CTA. Finally, we show that CTA-based collateral scores that take into account regional variability in pial arterial filling are better in predicting follow-up infarct volumes than scores that do not.

Assessing regional variability in collateral status is clinically relevant because it likely helps clinicians predict posttreatment regional tissue fate in a better manner. Moreover, improving methods of assessing collaterals on CTA is important because collaterals affect clinical decision-making in acute ischemic stroke by predicting tissue fate and clinical outcomes. ${ }^{9,10}$ Good collateral scoring appears to be associated with better clinical prognosis in patients with AIS. ${ }^{11}$ Alternatively, poor collaterals are associated with poorer outcomes and even hemorrhagic transformation. ${ }^{12}$

Our results show that approximately $11.5 \%$ of sCTA scans are acquired in the very early arterial phase or the late venous phase. As noted in previous studies, mistiming of CTA acquisition, especially with sCTAs, can result in mislabelling of collateral status. $^{13,14}$ Rate of contrast injection, time between contrast injection and image acquisition, and patient factors, including low 
cardiac ejection fraction, may introduce variability in assessment of collateral assessment with sCTA. ${ }^{12,15}$ sCTA may capture anterior dominant patterns before the flow of contrast is sufficient in the posterior collateral circulation for collateral assessment; PCA-MCA filling may be slower than the ACA-MCA territory. ${ }^{16}$ These deficiencies with SCTA can be addressed to a significant extent using multiphase CTA. ${ }^{13}$

Limitations of our study include relatively small sample size and the use of a single evaluator trained in the use of $\mathrm{MGH}$, ASITN, and CC Scores.

\section{Conclusion}

Collateral assessments in patients with acute ischemic stroke are best done using CTA, preferably with adequate temporal resolution and by assessing regional variability. Moreover, ACA-MCA and MCA-PCA collaterals should be evaluated separately because the ASITN score and MGH score may not account for collateral regional variability.

\section{ACKNOWLEDGEMENTS AND Funding}

The authors thank the University of Calgary Department of Clinical Neurosciences, the Hotchkiss Brain Institute, and the Calgary Stroke Program for their ongoing support, and the reviewers at Canadian Journal of Neurological Sciences for their hard work and consideration.

The Identifying Novel Approaches to Optimize Arterial Imaging Interpretation for Predicting and Measuring Recanalization Whatever the Treatment and to Optimize Parenchymal Imaging Interpretation for Prediction of Early Neurological Recovery After Recanalization Using Serial CT Angiography (INTERRSeCT) study was funded through a grant from the Canadian Institute of Health Research (CIHR). BKM holds the current Heart and Stroke Foundation/University of Calgary Professorship in Stroke Imaging and a CIHR New Investigator Award.

\section{Disclosures}

BKM reports the following disclosures: Canadian Institute of Health Research (CIHR): grant recipient, CIHR grant, New Investigator Award recipient, CIHR award. Heart and Stroke Foundation: professorship, and award. CC, AT, SIS, EQ, ASAL, $\mathrm{MB}, \mathrm{CD}, \mathrm{MA}, \mathrm{AMD}$, and MG have nothing to disclose.

\section{REFERENCES}

1. Christoforidis GA, Karakasis C, Mohammad Y, Caragine LP, Yang M, Slivka AP. Predictors of hemorrhage following intra-arterial thrombolysis for acute ischemic stroke: the role of pial collateral formation. AJNR Am J Neuroradiol. 2009;30: $165-70$.
2. Demchuk AM, Menon B, Goyal M. Imaging-based selection in acute ischemic stroke trials - a quest for imaging sweet spots. Ann N Y Acad Sci. 2012;1268:63-71.

3. Miteff F, Levi CR, Bateman GA, Spratt N, McElduff P, Parsons MW. The independent predictive utility of computed tomography angiographic collateral status in acute ischaemic stroke. Brain. 2009;132:2231-8.

4. Souza LC, Yoo AJ, Chaudhry ZA, et al. Malignant CTA collateral profile is highly specific for large admission DWI infarct core and poor outcome in acute stroke. AJNR Am $\mathrm{J}$ Neuroradiol. 2012;33:1331-6.

5. Menon BK, O'Brien B, Bivard A, et al. Assessment of leptomeningeal collaterals using dynamic ct angiography in patients with acute ischemic stroke. J Cereb Blood Flow Metab. 2013;33:365-71.

6. Garcia-Tornel A, Carvalho V, Boned S, et al. Improving the evaluation of collateral circulation by multiphase computed tomography angiography in acute stroke patients treated with endovascular reperfusion therapies. Interv Neurol. 2016;5:209-17.

7. McVerry F, Liebeskind DS, Muir KW. Systematic review of methods for assessing leptomeningeal collateral flow. AJNR Am J Neuroradiol. 2012;33:576-82.

8. Rodriguez-Luna D, Dowlatshahi D, Aviv RI, et al. Venous phase of computed tomography angiography increases spot sign detection, but intracerebral hemorrhage expansion is greater in spot signs detected in arterial phase. Stroke. 2014;45:734-9.

9. Goyal M, Demchuk AM, Menon BK, et al. Randomized assessment of rapid endovascular treatment of ischemic stroke. N Engl J Med. 2015;372:1019-30.

10. Leng X, Lan L, Liu L, Leung TW, Wong KS. Good collateral circulation predicts favorable outcomes in intravenous thrombolysis: a systematic review and meta-analysis. Eur J Neurol. 2016;23:1738-49.

11. Tan BY, Wan-Yee K, Paliwal P, et al. Good intracranial collaterals trump poor aspects (Alberta Stroke Program Early CT score) for intravenous thrombolysis in anterior circulation acute ischemic stroke. Stroke. 2016;47:2292-8.

12. Brunner F, Tomandl B, Hanken K, Hildebrandt H, Kastrup A. Impact of collateral circulation on early outcome and risk of hemorrhagic complications after systemic thrombolysis. Int J Stroke. 2014; 9:992-8.

13. Menon B, D'Esterre C, Qazi E, et al. Multiphase CT angiography- a new tool for the imaging triage of patients with acute ischemic stroke. Radiology. 2015;275:510-20.

14. Menon BK, Smith EE, Modi J, et al. Regional leptomeningeal score on $\mathrm{CT}$ angiography predicts clinical and imaging outcomes in patients with acute anterior circulation occlusions. AJNR Am J Neuroradiol. 2011;32:1640-5.

15. Soares BP, Tong E, Hom J, et al. Reperfusion is a more accurate predictor of follow-up infarct volume than recanalization: a proof of concept using ct in acute ischemic stroke patients. Stroke. 2010;41:e34-40.

16. Arsava EM, Vural A, Akpinar E, et al. The detrimental effect of aging on leptomeningeal collaterals in ischemic stroke. J Stroke Cerebrovasc Dis. 2014;23:421-6.

17. Riva M, Pappada GB, Papadakis M, et al. Hemodynamic monitoring of intracranial collateral flow predicts tissue and functional outcome in experimental ischemic stroke. Exp Neurol. 2012; 233:815-20. 